UDC 323.2

Submitted: 28.04.2021

LBC 66.2(2Poc)

Accepted: 01.06.2021

\title{
"DISTANT" COMMUNICATION: TRANSFORMATION OF INTERACTION BETWEEN RUSSIAN SOCIETY AND AUTHORITIES IN THE ERA OF THE GLOBAL PANDEMIC ${ }^{1}$
}

\author{
Sergey A. Pankratov \\ Volgograd State University, Volgograd, Russian Federation \\ Sergey I. Morozov \\ Volgograd State University, Volgograd, Russian Federation
}

\begin{abstract}
Introduction. The article is devoted to the identification and analysis of the dominant trends in the transformation of forms and technologies of communication used by the government and Russian society institutions in the context of the COVID-19 spread. The attention is focused on the characteristics of socio-political factors that determine the level of trust/distrust of citizens and representatives of various social groups to intentions and actions of the authorities and administration at the federal, regional and municipal levels in the Russian Federation to overcome the consequences of the global pandemic in the process of communication. Methods. The communicative practices of public and civil institutions are revealed in the context of interpreting the specifics of the existing public space and public policy of modern Russia. The theoretical and methodological basis of the research are the political-communicative and action-activist approaches, the spatial dimension of political processes principles, which make it possible to rely on the systemic vision of the information and discursive, practical and management elements of the multidimensional concept of public policy. The work uses the methods of political comparative studies, forecasting, interpretation of empirical data obtained by leading Russian and foreign research centers, as well as by the authors in the framework of their grant research. Results. An attempt was made to conduct political analysis of the dominant negative and positive factors revealing the specifics of the COVID-19 spread in the Russian Federation from the point of view of the everyday practices of modern Russian society and the consolidated institutional system of public administration. The authors trace the link between the situation of uncertainty resulting from the spread of the global threat, the desire to ensure international and national security, as well as the transformation of forms and technologies of communication between citizens, public institutions, the state. The real and potential resources of communication between society and the authorities for building an effective system to minimize the negative consequences of the pandemic for representatives of various socio-demographic, professional, and status-role groups, that are included in the structures of discussion, decision-making and implementation, are highlighted. The results of theoretical and empirical studies revealing a public opinion on the impact of COVID-19 on the socio-political process in modern Russia are interpreted. Discussion. The question of the forms and technologies of communication between the actors of modern public policy in the significant $\vec{\widehat{ }}$ decisions making process in the context of strengthening destructive factors and the institutionalization of a "riskgenerating" society remains poorly studied.

Key words: civil society, government institutions, Russia, COVID-19, communication, public policy, transformation, risk minimization.

Citation. Pankratov S.A., Morozov S.I. "Distant" Communication: Transformation of Interaction Between Russian Society and Authorities in the Era of the Global Pandemic. Vestnik Volgogradskogo gosudarstvennogo universiteta. Seriya 4. Istoriya. Regionovedenie. Mezhdunarodnye otnosheniya [Science Journal of Volgograd State University. History. Area Studies. International Relations], 2021, vol. 26, no. 3, pp. 172-181. (in Russian). DOI: https://doi.org/10.15688/jvolsu4.2021.3.15
\end{abstract}




\title{
«ДИСТАНТ» КОММУНИКАЦИИ: ТРАНСФОРМАЦИЯ ВЗАИМОДЕЙСТВИЯ РОССИЙСКОГО ОБЩЕСТВА И ВЛАСТИ В ЭПОХУ ГЛОБАЛЬНОЙ ПАНДЕМИИ ${ }^{1}$
}

\author{
Сергей Анатольевич Панкратов \\ Волгоградский государственный университет, г. Волгоград, Российская Федерация \\ Сергей Иванович Морозов \\ Волгоградский государственный университет, г. Волгоград, Российская Федерация
}

\begin{abstract}
Аннотация. Введение. Статья посвящена выявлению и анализу доминирующих тенденций трансформации форм и технологий коммуникации институтов российского общества и власти в условиях распространения COVID-19. При этом внимание акцентируется на характеристике социально-политических факторов, определяющих уровень доверия / недоверия граждан, представителей различных социальных групп в процессе коммуникации к намерениям и действиям органов власти и управления федерального, регионального и муниципального уровней в РФ по преодолению последствий глобальной пандемии. Memoдbl. Коммуникативные практики общественных и гражданских институтов раскрываются в контексте интерпретации специфики сложившихся публичного пространства и публичной политики современной России. В качестве теоретико-методологической основы исследования выступает политико-коммуникативный и деятельностно-активистский подходы, принципы пространственного измерения политических процессов, что позволяет опираться на системное видение информационно-дискурсивных, деятельностных и управленческих элементов многомерного концепта публичной политики. В работе используются методы политической компаративистики, прогнозирования, интерпретации эмпирических данных, полученных ведущими отечественными и зарубежными научными центрами, а также при непосредственном участии авторов в рамках реализации грантовой деятельности. Результаты. Предпринята попытка политологического анализа доминирующих негативных и позитивных факторов, раскрывающих специфику распространения COVID-19 в РФ с точки зрения повседневных практик современного российского общества и закрепленной институциональной системы государственного управления. Прослежена взаимосвязь между ситуацией неопределенности, возникшей в результате распространения глобальной угрозы, стремлением к обеспечению международной и национальной безопасности, а также трансформацией форм и технологий коммуникации граждан - общественных институтов - государства. Выделены реальные и потенциальные ресурсы коммуникации общества и власти по выстраиванию эффективной системы минимизации негативных последствий пандемии для представителей различных социально-демографических, профессиональных и статусно-ролевых групп, включенных в структуры обсуждения, принятия и реализации решений. Интерпретированы результаты теоретических и эмпирических исследований, раскрывающих срез общественного мнения по вопросам влияния COVID-19 на социально-политический процесс в современной России. Обсуждение. Малоизученным остается вопрос о формах и технологиях коммуникации акторов современной публичной политики в процессе принятия значимых решений в контексте усиления деструктивных факторов и институционализации «рискогенного» общества. Вклад авторов. С.А. Панкратов разработал теоретическую базу исследования и осуществил общую научную редакцию статьи. С.И. Морозов проанализировал доминирующие тенденции взаимодействия институтов власти и общества в контексте преодоления распространения COVID-19.

Ключевые слова: гражданское общество, институты власти, Россия, COVID-19, коммуникация, публичная политика, трансформация, минимизация рисков.

Цитирование. Панкратов С. А., Морозов С. И. «Дистант» коммуникации: трансформация взаимодействия российского общества и власти в эпоху глобальной пандемии // Вестник Волгоградского государственного университета. Серия 4, История. Регионоведение. Международные отношения. - 2021. - Т. 26, № 3. C. 172-181.-DOI: https://doi.org/10.15688/jvolsu4.2021.3.15
\end{abstract}




\section{ПРАКТИКИ ВЗАИМОДЕЙСТВИЯ ИНСТИТУТОВ ВЛАСТИ И ОБЩЕСТВА}

Введение. Первая четверть XXI в. ознаменовалась несколькими волнами пандемий. В 2002 г. в Китае появилась атипичная пневмония (SARS - острый респираторный синдром), источником которой выступили циветты - мелкие млекопитающие. Погибло около 800 человек из 8000 заболевших. В 2003-2008 гг. стремительное распространение приобрели свиной и птичий грипп, передаваемые от животных человеку, в результате чего 227 человек погибло из 361 заразившегося. В 2009 г. свиным гриппом были инфицированы 255 тыс. жителей Мексики и США, из которых около трех тысяч умерло, и Всемирная организация здравоохранения (BО3) была вынуждена объявить официально состояние пандемии. В 2012 г. через летучих мышей произошло распространение коронавируса ближневосточного респираторного синдрома (MERS, 2012), которым заразилось 2,5 тысячи и погибло около 900 человек. В 2014 2015 гг. 28 тыс. человек заразилось лихорадкой Эболы при 11000 смертей в основном в Западной Африке. Носителями вируса вновь выступили летучие мыши, заразившие других животных, а от тех болезнь передалась человеку $[4 ; 19]$.

На конец 2019 - начало 2020 г. пришлось распространение COVID-19, споры об источнике вируса ведутся по настоящее время. Человечеству не удалось даже к середине 2021 г. справиться с этой глобальной угрозой, при том, что на разработку и использование вакцин, минимизацию последствий пандемии затрачены политические, социально-экономические, научные и иные ресурсы развитых стран мира. [18] Более того, по словам директора Института им. Н.Ф. Гамалеи, академика А. Гинцбурга, нас, возможно, ждет еще один этап эпидемии коронавируса - заражение вирусом сельскохозяйственных и домашних животных. С точки зрения ученого, человечеству необходимо научиться жить и противостоять длительное время COVID-19.

В своем выступлении на заседании дискуссионного клуба «Валдай», посвященном теме «Уроки пандемии и новая повестка: как превратить мировой кризис в возможность для мира», Президент РФ В.В. Путин отметил: «Коронавирус не отступил, к сожалению, и представляет до сих пор серьезную угрозу...
Трудно было представить, что в технологически продвинутом, нашем XXI веке даже в самых благополучных, состоятельных странах человек может остаться беззащитным перед, казалось бы, не такой уж и фатальной инфекцией, не такой уж и страшной угрозой. А жизнь показала, что дело не только в уровне развития медицинской науки с ее подчас фантастическими достижениями. Оказалось, что не менее, а может, и гораздо важнее другое организация и доступность системы массового здравоохранения. Ценности взаимопомощи, служения и самопожертвования, объединяющие людей, - вот что оказалось важно. Ответственность, собранность и честность власти, ее готовность воспринять запрос общества и одновременно четко, аргументированно объяснить логику и последовательность принимаемых мер, чтобы не дать страху побороть и разобщить общество, а, напротив, вселить уверенность, что как бы ни было трудно, мы вместе преодолеем все испытания» [17].

Таким образом, в рамках политологического дискурса актуализировалась потребность в осмыслении тенденций трансформации взаимодействия общества и властных структур всех уровней для обоснования наиболее эффективных форм и технологий коммуникации в условиях глобальной неопределенности развития, минимизации негативных последствий для российского общества и государства.

Методы и материалы. Теоретико-методологическую базу исследования составляют политико-коммуникативный и деятельностно-активистский подходы, что позволяет использовать системное видение информационно-дискурсивных, деятельностных и управленческих элементов многомерного концепта публичной политики. В рамках данной статьи авторы интерпретируют публичную политику как целенаправленное создание условий и факторов вовлечения социума и его институциональных образований, отдельных граждан в процесс обсуждения и принятия общезначимых политических решений. При этом учитывается феномен сетевизации публичного управления, публичной политики и публичного пространства, характеризуемый интенсивным использованием информационно-коммуникативных технологий и формированием новой информационной экосистемы [9]. 
Трансформация коммуникативных практик общественных и гражданских институтов анализируется в контексте процессов выявления, предупреждения и устранения реальных и потенциальных опасностей, связанных с конкретными проявлениями глобальной угрозы в национальном и региональном масштабах, а также исторически сложившейся специфики публичного пространства современной России [16]. В работе применяются методы политической компаративистики, прогнозирования, интерпретации эмпирических данных, полученных ведущими отечественными и зарубежными научными центрами, а также при непосредственном участии авторов.

Анализ. Первый официально зарегистрированный случай заражения коронавирусом в РФ произошел 1 марта 2020 г. - у россиянина, вернувшегося из Италии. 27 марта было прекращено авиасообщение со всеми странами, а спустя три дня распоряжением правительства было ограничено движение через все пункты пропуска через государственную границу России. С 30 марта по 5 апреля 2020 г. Президентом РФ В.В. Путиным была объявлена первая нерабочая неделя в связи с эпидемией коронавируса. Но выходные закончились лишь после 12 мая 2020 г., когда часть сотрудников вышла на работу в офлайн-формате, а другая - до сих пор продолжает работать дистанционно. Ограничительные меры функционируют в зависимости от эпидемиологической ситуации на конкретных территориях.

На 1 марта 2021 г. в Российской Федерации около 4,2 млн человек, переболевших с начала пандемии. Если добавить условно 20$30 \%$, перенесших болезнь безсимптомно и около 4 млн привитых, то это около 8-9 млн человек, что лишь 5,7-6 \% от 146 млн жителей страны. По мнению специалистов, для замедления темпов распространения инфекции необходимо сформировать иммунитет у 60 70 \% граждан страны [11].

Следует согласиться с позицией Председателя Конституционного суда РФ В.Д. Зорькина о том, что в период пандемии Россия, как и многие страны мира, столкнулась с тремя основными проблемами. «Во-первых - это распределение и перераспределение полномочий органов государственной власти во вре- мя борьбы с инфекцией. Во-вторых - это проблема политических прав, которые подверглись наиболее существенным ограничениям (например, право на участие в управлении делами государства или свобода собраний). В-третьих - меры социальной поддержки граждан и экономики в связи с пандемией. При этом стало очевидно, что слабое государство не способно решить эти проблемы и не в состоянии справиться с таким глобальным вызовом» [7].

Относительно общая характеристика состояния российского общества и государства в этот период нашла отражение в результатах социологического исследования Высшей школы экономики 2020 г., которое было направлено на выявление социального самочувствия и настроения россиян в условиях пандемии [13].

Во-первых, отмечается, с одной стороны, трудность, с другой стороны, своевременность принятия решения государством об «остановке экономики и социального общения», что повлекло реальное падение доходов населения и разработку программ частичной компенсации отдельных граждан, семей и бизнеса.

Во-вторых, неприятие, озлобленность части населения на формальные требования федеральных и региональных властей соблюдать ограничительные меры (ношение масок, соблюдение дистанции и т. д.) при невозможности их обеспечения в транспорте и иных общественных местах, особенно в первый период пандемии.

В-третьих, возрастание требований к решительным и разнообразным действиям государства, в том числе в условиях чрезвычайной ситуации, с $29 \%$ в 2016 г. до $34 \%$ в 2020 году.

B-четвертых, наметилась смена приоритетов: если в 2018 г. большинство респондентов (31\%) считали, что государство должно обеспечить необходимый минимум всем гражданам, то в условиях пандемии (ограниченных возможностей в стране) около $40 \%$ приоритет в поддержке приемлемого уровня жизни отдали людям, попавшим в трудную жизненную ситуацию (потеря работы и др.).

B-пятых, распространение COVID-19 активизировало спрос и предложение на кол- 


\section{ПРАКТИКИ ВЗАИМОДЕЙСТВИЯ ИНСТИТУТОВ ВЛАСТИ И ОБЩЕСТВА}

лективное преодоление проблем через солидарность и взаимопомощь (волонтерство), а также способность повлиять на ситуацию в городе, районе, непосредственном месте проживания.

В-шестых, увеличились потоки внутренней миграции, связанные с поиском работы (особенно среди молодежи) и проживания вне городских агломераций (переселение ближе к природе и возможности безопасного ограниченного общения с близкими) [8].

В этот сложный период, с нашей точки зрения, происходит переформатирование стилистических особенностей коммуникативного взаимодействия власти и общества, отдельных граждан, что было вызвано:

- востребованностью на гражданскую доверительность в распространении и получении информации, при принятии решений, изначально продуцирующих общественный резонанс в публичном пространстве;

- увеличением потока «кризисной» информации, несущей негативный контент на различные группы и акторов политического процесса, в том числе в сегменте публичной коммуникации;

- резким переходом органов власти, субъектов межличностного и группового общения в дистанционный формат, и, как следствие, восприятием обычного офлайн-общения через архаические и инновационные переменные;

- распространением международного опыта выстраивания системы коммуникаций власти и общества в контексте увеличения протестных акций, вызванных как ограничительными мерами, связанными с пандемией, так и обострением конкурентной политической борьбы в связи с приближающимися и проходящими выборами в различные органы власти;

- апробацией цифровых технологий с элементами искусственного интеллекта в публичном пространстве регионов, имеющих специфику как в уровне сформированности цифровой культуры, так и восприятия глобальной пандемии сквозь призму санкционного противостояния РФ и ряда зарубежных стран институционализации форм гибридной войны;

- усилением ксенофобских и экстремистских настроений, что во многом спровоцировано бездоказательной фейковой компанией в
СМИ, Интернете, социальных сетях, выступлениях отдельных политиков в поисках «врага» (стран, этнических групп и т. д.), первопричин распространения COVID-19 в глобальном масштабе.

Существенной характеристикой в восприятии гражданами и значительной частью общества намерений и действий власти на различных этапах внедрения противоэпидемиологических мер выступила эмоциональная составляющая, во многом противостоящая (игнорирующая) реальным фактам и научной экспертизе, подвергающая сомнению легитимность властных институтов, решений, традиционных лидеров общественного мнения.

Диспозитив доверия между властью и обществом во многом выстроился по линии ограничения / необходимости соблюдения политических и гражданских прав, обусловленных эпидемиологической обстановкой. Как показывает исторический опыт, наиболее эффективно, в сжатые сроки с крупными масштабами эпидемий справлялись авторитарные режимы (например, пандемия испанки в Европе и России первой четверти XIX в., в начале XX в.). В нынешней ситуации распространения COVID-19 пример эффективных и результативных мер по минимизации последствий как в здравоохранении, социальной сфеpe, так и экономике демонстрирует Китай.

В настоящее время в большинстве случаев целесообразно учитывать характеристики «гибридности» режимов: тритрадицию доминирования тех или иных функциональных особенностей государства; уровень доверия национальным лидерам и органам власти в системе разделения властей; наличие институциональной «укорененности» влияния гражданского общества на все уровни управления; включенность СМИ в публичный диалог власти и общества и т. д. При этом в большинстве случаев, по нашему мнению, современные государства не могут себе позволить принудительную массовую вакцинацию населения вопреки его воле, использование военной силы, физических репрессий, насилия в иных формах.

С нашей точки зрения, за прошедший год противодействия COVID-19 в РФ, как и в мире, трансформировалась экология медиапространства, что проявляется, с одной сторо- 
ны, в росте количества и разнообразии каналов коммуникации, а, с другой стороны, падении доверия населения к государственным и политическим институтам. Налицо фрагментация источников политической информации, размытость запросов на информационную открытость и достоверность в рамках реализации национальных и региональных публичных политик. Альтернативность источников информации подталкивает потребителей (граждан, их объединений и т. д.) обращаться к теориям заговора, фейкам и др. В процесс институционализации сетевого публичного и информационного пространства особенно активно включена молодежь.

Следует признать, что у большинства представителей «поколения Z»-нынешних 1523-летних юношей и девушек - важнейшей чертой выступает «жизнь» в мире высоких технологий, где Интернет используется около 98 \% принадлежащих к данной когорте. При этом в социальных сетях молодые люди проводят более пяти часов в день, проверяя обновления каждые тридцать минут. Онлайн-коммуникация актуализирует стиль жизни лидеров общественного мнения, поведенческие образцы как формы проявления суб- и контркультуры, ценностные и политические предпочтения.

С помощью использования новых форм и технологий коммуникации молодежь выражает неудовлетворенность между декларируемыми целями, мечтой и реальностью, повседневными практиками жизнедеятельности. Все чаще данные каналы коммуникации используются в качестве достижения «общественных расколов» через манипуляции в сфеpax межпоколенческих, этноконфессиональных, идейно-политических, социально-экономических и иных взаимоотношений. Здесь же проявляется и мобилизационная составляющая Интернет - сетевых коммуникаций как для артикулирования общедемократических положений, в том числе соблюдения и правовой защиты прав, свобод человека и гражданина, так и выражения обеспокоенности, страха о возрастании проявлений несправедливости в сфере здравоохранения, образования, уровня жизни и т. д.

Согласно данным Фонда развития интернет каждые 83 секунды в сети рождается хейт (ненависть - англ.), вводя в пространство ком- муникации хейтера (ненавистника - англ.) [6]. Феномен деиндивидуализации, «маска» анонимности позволяет демонстрировать наиболее радикальные позиции, не соотносящиеся с моралью и нравственностью.

В условиях распространения COVID-19 в отечественном сегменте Рунета специалистами было выделено три волны распространения хейта (до ста тысяч сообщений в день). Первая волна длилась на начальном этапе распространения пандемии, характеризовалась непониманием и растерянностью отдельных групп населения и проявилась в ажиотажном спросе на медицинские маски, лекарства, продукты питания и др. Вторая волна связана с нахождением граждан в самоизоляции, распространением противоречивых новостей как в анонимном формате, так и от международных СМИ, Всемирной организации здравоохранения (BО3). Политический окрас данному этапу придавали сообщения о том, что власти скрывают реальные последствия распространения COVID-19 - на лицо «кремлевский» и «всемирный» заговор. Третья волна связана с выходом из самоизоляции и продолжается по настоящее время. Хейтеры комментируют по 35-50 тысяч сообщений в день про «чипизацию вакцинами». Значительный сегмент общественного мнения формируется под воздействием фейковых и хейтовых сообщений в Сети.

По словам главы компании «Интернетрозыск» И. Бедерова, только в 2020 г. в отечественном сегменте Интернета было зарегистрировано 5,9 тыс. доменов, содержащих в названии понятия «пандемия», «коронавирус», «вакцина», треть из которых опасна с точки зрения потери пользовательских и иных данных. Роскомнадзор заблокировал более 500 сайтов, содержащих сведения о незаконной торговле лекарственными препаратами от COVID-19 [1].

Ярким примером реакции государства на распространение фейков о коронавирусе явилось решение Мосгорсуда о штрафе журналисту и блогеру А. Тюняеву в размере 400 тыс. рублей. На своем YouTube-канале он разместил видеоролик, в котором говорилось, что COVID-19 реально выступает «болезнью Фейгельсона - Якобсона» и опасна лишь для лиц еврейской и армянской национальностей. 


\section{ПРАКТИКИ ВЗАИМОДЕЙСТВИЯ ИНСТИТУТОВ ВЛАСТИ И ОБЩЕСТВА}

В другом ролике, распространяемом А. Тюняевым, население информировалось о том, что под видом борьбы с коронавирусом у людей изымают внутренние органы и продают их для трансплантации [5].

Большая работа ведется по пресечению пропаганды национализма, ксенофобии, экстремизма. В 2020 г. полицией было выявлено 500 преступлений экстремистской направленности. Более ста тысяч экстремистских интернет-ресурсов было заблокировано, свыше 7,5 тысяч материалов - удалено [15].

В этой ситуации актуализируется вопрос о необходимости, возможности контролировать основные информационные каналы, от традиционных до цифровых, от национальных до имеющих отношения к зарубежным базам, распространения социальных сетей. Одним из «популярных» предложений изменения данной ситуации выступило правовое закрепление отмены анонимности в Сети, удаление хейтерских комментариев.

Вместе с тем общение в Сети инкогнито - это практика современного демократического общества. С нашей точки зрения, гораздо эффективнее и целесообразнее зондирование, прогнозирование и нейтрализация деструктивных информационных волн, «перехват» информационной повестки дня и профессиональное разоблачение фейков, последовательное формирование информационной культуры населения.

В публичном пространстве ряда стран и регионов, в том числе России, коммуникация власти и общества «состоялась» в форме протестных действий со стороны представителей различных социальных групп. Антиковидные протесты прошли в большинстве стран, где государство активно реализовывало ограничительные меры по распространению пандемии. Так, в Германии в 2020 г. акции протеста были одними из самых продолжительных и многочисленных (от 5000 до 40000 человек) в Евросоюзе.

В экспертном докладе Фонда развития гражданского общества (ФоРГО) выделено несколько особенностей данных протестов: «высокий уровень внутренней организации и появление новых "харизматических фигур, претендующих на то, чтобы стать видными общественно-политическими деятелями"; массовое вовлечение в акции политически индифферентных людей и организаций и их политизация. Побудительным мотивом стало несогласие с ограничением гражданских прав; постепенная политизация самого протеста, переход “от требований, связанных с отменой карантинных ограничений, к критике курса федерального правительства"» [10].

По словам главы ФоРГО К. Костина, в ФРГ наблюдается тип протеста макрополитического происхождения. В России, с точки зрения эксперта, протестное движение имеет микрополитические основания, связанные с конкретным событием (ситуация вокруг оппозиционного блогера А. Навального).

В настоящее время в публичном пространстве РФ актуализировался вопрос об источниках и факторах солидаризации социума, граждан, их общественных объединений и государства. «Принцип солидарности по своей сути предполагает коллективную ответственность государства и общества за индивидуальные потребности граждан, являясь основой функционирования социальных систем» [3]. Как отмечает Н.С. Григорьева, «доверие в наши дни можно заслужить двумя определенными качествами: компетентностью (способностью выполнять обещания) и этичным поведением (правильными поступками и работой на благо общества). В настоящее время ни один институт граждане не считают одновременно компетентным и этичным. Модель доверия поменялась с вертикальной модели «сверху вниз», зависящей от традиционных лидеров, на горизонтальную, при которой люди больше доверяют друзьям, родственникам и “таким же людям, как они сами"» $[2$, с. 152$]$.

С точки зрения авторов, чем раньше будет предложен властью обществу оптимальный для большинства населения образ будущего, тем быстрее произойдет снижение социально-политической напряженности и протестной активности. Солидарность личности общества - власти следует рассматривать через объединение ресурсов и возможностей для достижения общих целей, без доминирования «высоких абстракций» коллективного и «эгоизма» индивидуального интереса [14, c. 148]. Фактически суть трансформации коммуникативного взаимодействия общества и 
власти должна быть зафиксирована в новом «социальном контракте», отражающем обмен ожиданиями между согражданами, между гражданами и общественными институтами, между гражданами и властью (государством) по поводу основных прав и свобод в условиях рискогенных факторов, оказывающих значительное влияние на повседневные социальные и политические практики.

В публичном пространстве России отчетливо прослеживается конкурентное противостояние в доминировании принципов «свободы», «справедливости», «эффективности государства». По нашему мнению, в условиях распространения глобальных эпидемий и иных угроз правильной стратегией в поведении властей выступает ее открытость, укрепляющее доверие и устойчивое развитие, построенное на доверии.

Результаты. Как показывают результаты теоретических и эмпирических исследований, во время распространения пандемии органами власти в регионах РФ было апробировано несколько моделей взаимодействия как с институтами гражданского общества, так и социумом в целом. Условно их можно обозначить следующим образом:

- власть выступает в роли «заботливого родителя», оставляя общественным институтам функции дорогих, внимающих «старшим» и беспрекословно готовым к выполнению любых их «самых правильных» решений;

- власть обличена технократическими полномочиями по трансляции до различных социальных групп и каждого проживающего на вверенной территории стратегии противодействия COVID-19, выработанной федеральным центром и организацией совместно с гражданскими институтами тактических мероприятий с учетом развития ситуации в каждом отдельном регионе;

- «независимой самоорганизации» граждан и организаций по минимизации негативных последствий пандемии с «отстраненностью» органов власти (нет реальной помощи, но нет и противодействия) и параллельное функционирование властных и гражданских структур в выбранном секторе публичного пространства региона;

- патерналистское доминирование органов власти по всем вопросам, связанным с противодействием угрозам, вызванным распространением пандемии. При этом население и гражданские институты рассматриваются лишь в качестве «приводных ремней» по реализации решений, принятых исполнительной властью, несущей ответственность в лице руководителя субъекта РФ за ситуацию в регионе.

Данные типологические модели выступают в качестве доминирующих, предполагая их «Гибридность» в практиках взаимодействия общества и власти на региональном и местном (муниципальном) уровнях. Важно подчеркнуть, что выбор данных моделей коррелировался с решением конкретных проблем, вызванных пандемией или сопутствующих ей: «снятие» общественного напряжения; принятие и реализация популярных / непопулярных решений; сохранение / подъем рейтинга региона в целом или его главы; мобилизация властных и общественных институтов для проведения восстановительных мероприятий в экономической, социокультурной, политико-правовой и иных сферах жизнедеятельности.

Признавая тот факт, что в социальных сетях ведется активная целенаправленная деятельность «антиваксеров», нагружающих людей большим объемом дезинформационного материала, делая ставку на страхах по поводу побочных эффектов вакцин, с точки зрения авторов, следует использовать скоординированные действия власти, медицинских работников, СМИ на федеральном и региональном уровне, что позволит преодолеть нерешительность граждан в отношении вакцинирования и выработки коллективного иммунитета [12].

Совершенно очевидно, что взаимодействие общества и власти с возросшей интенсивностью не было бы возможно, если бы государство ранее не работало над цифровизацией своей деятельности. Применение цифровых технологий дает возможность принимать многие решения в пространстве Интернет, что позволяет констатировать возникновение элементов консенсусной демократии в РФ. При этом необходимо быть готовыми к разрешению нового противоречия между цифровой демократией и цифровым тоталитаризмом, демонстрирующим мощь и эффективность государства. 


\section{ПРАКТИКИ ВЗАИМОДЕЙСТВИЯ ИНСТИТУТОВ ВЛАСТИ И ОБЩЕСТВА}

\section{ПРИМЕЧАНИЕ}

${ }^{1}$ Исследование выполнено при финансовой поддержке РФФИ и Администрации Волгоградской области в рамках научного проекта № 19-411-340006 p_а «Социально-политическое проектирование публичного пространства и системы массовой коммуникации в регионах РФ (на примере Волгоградской области)».

The reported study was funded by RFBR and Volgograd Region Administration in the framework of research project no. 19-411-340006 p_a "Socio-Political Design of Public Space and Mass Communication System in the Regions of the Russian Federation (The Example of the Volgograd Region)".

\section{СПИСОК ЛИТЕРАТУРЫ}

1. Гаврилюк, А. Игры с разумом / А. Гаврилюк // Известия. $-2021 .-3$ февр. - С. 6.

2. Григорьева, Н. С. Граждане и общество в условиях пандемии COVID-19: общественные интересы versus личная свобода / Н. С. Григорьева // Государственное управление. Электронный вестник. -2021, февраль. - Вып. 84. - С. 147-164. - Электрон. текстовые дан. - Режим доступа: http://e-journal.spa.msu.ru/ uploads/vestnik/2021/vipusk_84._fevral_2021_g./ soziologija_upravlenija/grigorieva.pdf(дата обращения: 25.02.2021). - Загл. с экрана.

3. Григорьева, Н. С. Современное здравоохранение: политика, экономика, управление / Н. С. Григорьева, Т. В. Чубарова. - М. : Авторская академия, 2013. - $344 \mathrm{c}$.

4. Дубовенко, С. Мир во время чумы / С. Дубовенко // Профиль. - 2020. - № 9. - С. 22-27.

5. Егоров, И. Клик и штраф / И. Егоров // Российская газета. -2021. - 11 марта. - С. 8.

6. Емельяненко, В. Ненавижу, значит существую / В. Емельяненко // Российская газета. - 2021. 4 марта. - С. 7.

7. Зорькин, В. Д. Возвращение государства / В. Д. Зорькин // Российская газета. - 2021. 17 мая. - С. $1,4$.

8. Коньков, А. Е. Солидарность в политике современного государства / А. Е. Коньков // Государственное управление. Электронный вестник. 2020. - № 81. - С. 182-195. - Электрон. текстовые дан. - Режим доступа: http://e-journal.spa.msu.ru/ vestnik/item/81_2020konkov.htm (дата обращения: 25.02.2021). - Загл. с экрана.

9. Мирошниченко, И. В. Сетевая публичная политика и управление / И. В. Мирошниченко. М. : АРГАМАК-МЕДИА, 2016. - 296 с.

10. Мисливская, Г. Уроки немецкого / Г. Мисливская // Российская газета. - 2021. - 9 февр. - С. 6.
11. Невинная, И. Зарядка для антител / И. Невинная // Российская газета. - 2021. - 1 марта. - С. 1, 5.

12. Невинная, И. Прививка - вторая натура / И. Невинная // Российская газета. - 2021. - 21 апр. C. 5 .

13. Овчарова, Л. Шоковая пандемия / Л. Овчарова // Известия. - 2021. - 4 марта. - С. 6.

14. Окара, А. Н. Солидаризм: Забытая идеология XXI в. / А. Н. Окара // Политическая наука. 2013. - № 4. - C. 146-155.

15. Поздняков, Н. Расставить сеть / Н. Поздняков, М. Ходыкин // Известия. - 2021. - 4 марта. C. $2-3$.

16. Публичная политика в России: по итогам проекта «Университет Калгари - Горбачев-Фонд». М. : Альпина Бизнес Букс, 2005. - 358 с.

17. Путин, В. В. Выступление на итоговой пленарной сессии XVII ежегодного заседания Международного дискуссионного клуба «Валдай» / В. В. Путин. - Электрон. текстовые дан. - Режим доступа: http://www.kremlin.ru/events/president/ news/64261 (дата обращения: 25.02.2021). - Загл. с экрана.

18. Agartan, T. I. COVID-19 and WHO: Global Institutions in the Context of Shifting Multilateral and Regional Dynamics / T. I. Agartan, S. Cook, V. Lin // Global Social Policy. - 2020. - Vol. 20, iss. 3. - P. 367-373.

19. Ekpenyong, A. COVID-19: Reflecting on the Role of the WHO in Knowledge Exchange Between the Global North and South / A. Ekpenyong, M. S. Pacheco // Global Social Policy. -2020. - Vol. 20, iss. 3. - P. 388-392.

\section{REFERENCES}

1. Gavrilyuk A. Igry s razumom [Mind Games]. Izvestiya, 2021, February 3, p. 6.

2. Grigoreva N.S. Grazhdane i obshchestvo v usloviyah pandemii COVID-19: obshchestvennye interesy versus lichnaya svoboda [Citizens and Society in the face of COVID-19 Pandemic: Public Interest versus Individual Freedom]. Gosudarstvennoe upravlenie. Elektronnyj vestnik [E-journal. Public Administration], February 2021, iss. 84, pp. 147-164. URL: http://e-journal.spa.msu.ru/uploads/vestnik/ 2021/vipusk_84._fevral_2021_g./soziologija_ upravlenija/grigorieva.pdf (accessed 25 February 2021).

3. Grigoreva N.S., Chubarova T.V. Sovremennoe zdravoohranenie: politika, ekonomika, upravlenie [Modern Public Health: Politics, Economics, Management]. Moscow, Avtorskaya akademiya Publ., 2013.344 p.

4. Dubovenko S. Mir vo vremya chumy [World in Time of Plague]. Profil, 2020, no. 9, pp. 22-27. 
5. Egorov I. Klik i shtraf [Click and Penalty]. Rossijskaya gazeta, 2021, March 11, p. 8.

6. Emelyanenko V. Nenavizhu, znachit sushchestvuyu [I Hate, Therefore I Am]. Rossijskaya gazeta, 2021, March 4, p. 7.

7. Zorkin V.D. Vozvrashchenie gosudarstva [Return of the State]. Rossijskaya gazeta, 2021, May 17, pp. 1,4 .

8. Konkov A.E. Solidarnost v politike sovremennogo gosudarstva [Solidarity in Modern State Policy]. Gosudarstvennoe upravlenie. Elektronnyj vestnik, 2020, no. 81, pp. 182-195. URL: http://e-journal.spa.msu.ru/vestnik/item/81_ 2020konkov.htm (accessed 25 February 2021).

9. Miroshnichenko I.V. Setevaya publichnaya politika i upravlenie [Network Public Policy and Management]. Moscow, ARGAMAK-MEDIA Publ., 2016. 296 p.

10. Mislivskaya G. Uroki nemeckogo [German Lessons]. Rossijskaya gazeta, 2021, February 9, p. 6.

11. Nevinnaya I. Zaryadka dlya antitel [Charging for Antibodies]. Rossijskaya gazeta, 2021, March 1, pp. 1,5 .

12. Nevinnaya I. Privivka - vtoraya natura [Vaccination is the Second Nature]. Rossijskaya gazeta, 2021, April 21, p. 5.

13. Ovcharova L. Shokovaya pandemiya [Shock Pandemic]. Izvestiya, 2021. March 4, p. 6.
14. Okara A.N. Solidarizm: Zabytaya ideologiya XXI v. [Solidarism: Forgotten Ideology of the $21^{\text {st }}$ Century]. Politicheskaya nauka [Political Science], 2013, no. 4, pp. 146-155.

15. Pozdnyakov N., Hodykin M. Rasstavit set [Arrange the Network]. Izvestiya, 2021, March 4, pp. 2-3.

16. Publichnaya politika v Rossii: po itogam proekta «Universitet Kalgari - Gorbachev-Fond》 [Public Policy in Russia: Based on the Results of the "University of Calgary - Gorbachev Foundation Project”]. Moscow, Alpina Biznes Buks Publ., 2005. $358 \mathrm{p}$.

17. Putin V.V. Vystuplenie na itogovoj plenarnoj sessii XVII ezhegodnogo zasedaniya Mezhdunarodnogo diskussionnogo kluba «Valdaj» [Speech at the Final Plenary Session of the $17^{\text {th }}$ Annual Meeting of the Valdai International Discussion Club]. URL: http://www.kremlin.ru/events/president/news/ 64261 (accessed 25 February 2021).

18. Agartan T.I., Cook S., Lin V. COVID-19 and WHO: Global Institutions in the Context of Shifting Multilateral and Regional Dynamics. Global Social Policy, 2020, vol. 20, iss. 3, pp. 367-373.

19. Ekpenyong A., Pacheco M.S. COVID-19: Reflecting on the Role of the WHO in Knowledge Exchange Between the Global North and South. Global Social Policy, 2020, vol. 20, iss. 3, pp. 388-392.

\section{Information About the Authors}

Sergey A. Pankratov, Doctor of Sciences (Politics), Professor, Head of the Department of International Relations, Political Science and Area Studies, Volgograd State University, Prosp. Universitetsky, 100, 400062 Volgograd, Russian Federation, pankratov@volsu.ru, https://orcid.org/0000-0002-1733-730X

Sergey I. Morozov, Candidate of Sciences (Politics), Associate Professor, Department of International Relations, Political Science and Area Studies, Volgograd State University, Prosp. Universitetsky, 100, 400062 Volgograd, Russian Federation, morozovsi@volsu.ru, https://orcid.org/0000-0002-4802-9203

\section{Информация об авторах}

Сергей Анатольевич Панкратов, доктор политических наук, профессор, заведующий кафедрой международных отношений, политологии и регионоведения, Волгоградский государственный университет, просп. Университетский, 100, 400062 г. Волгоград, Российская Федерация, pankratov@volsu.ru, https://orcid.org/0000-0002-1733-730X

Сергей Иванович Морозов, кандидат политических наук, доцент кафедры международных отношений, политологии и регионоведения, Волгоградский государственный университет, просп. Университетский, 100, 400062 г. Волгоград, Российская Федерация, morozovsi@volsu.ru, https://orcid.org/0000-0002-4802-9203 